\title{
Toepassing van het concept EPA als verbinding tussen professionele activiteiten en CanMEDS competentie- gebieden: pilotstudie Physician Assistant Urologie
}

\author{
G. Spenkelink-Schut, Th.J. ten Cate, H.S.M. Kort
}

\section{Samenvatting}

Inleiding: In dit pilotonderzoek zijn voor het specialisme Urologie de zogenaamde Entrustable Professional Activities (EPA's) geïdentificeerd van de Physician Assistant (PA). Ook zijn aan de hand van het CanMEDS (Canadian Medical Education Directions for Specialists, 2005) framework de kerncompetenties geanalyseerd.

Methode: Urologen en PA's Urologie zijn met behulp van een semi-gestructureerde vragenlijst geïnterviewd. De verzamelde data en uitkomsten van deze interviews zijn uitgewerkt tot een tweedimensionale matrix van EPA's en CanMEDS competenties. Deze matrix is vervolgens door vijf experts geanalyseerd op volledigheid van de EPA's en op toepassing van de competentiegebieden van het CanMEDS framework. De antwoorden op de in de interviews gestelde open vragen over de items supervisie en vertrouwen bij het delegeren van EPA's zijn geanalyseerd volgens de Grounded Theory benadering.

Resultaten: In dit pilotonderzoek zijn 47 EPA's urologie gedetermineerd. De tweedimensionale matrix objectiveert de EPA's en de aan het CanMEDS framework gerelateerde kerncompetenties. Het leren uitvoeren van EPA's door de PA vereist supervisie en vertrouwen van de uroloog. EPA's aanleren gaat volgens de opeenvolgende stappen: kennis uitvragen, demonstreren, uitvoeren onder begeleiding, tot het uiteindelijk zelfstandig uitvoeren van de activiteiten. Bij het aanleren van een EPA dient de uroloog aanwezig te zijn ter observatie, bijsturing en beoordeling. Het opbouwen van wederzijds vertrouwen tussen uroloog en PA heeft tijd nodig en blijft een subjectief aspect. Naast een optimale communicatie is het aangeven van grenzen belangrijk.

Conclusie en beschouwing: Het pilotonderzoek levert een empirisch gefundeerd model voor de samenhang tussen EPA's en CanMEDS competenties. Het resultaat is bruikbaar voor scholing van de PA Urologie; nader onderzoek is noodzakelijk. (Spenkelink-Schut G, Cate ThJ ten, Kort HSM. Toepassing van het concept EPA als verbinding tussen professionele activiteiten en CanMEDS competentiegebieden: pilotstudie Physician Assistant Urologie. Tijdschrift voor Medisch Onderwijs 2008;27(5):230-238.)

\section{Inleiding}

Sinds de modernisering van de opleidingen tot medisch specialist is competentiegericht opleiden volgens de CanMEDS (Canadian Medical Education Directions for Specialists, 2005) methodiek de leidraad in Nederland. ${ }^{1-2}$ Zo heeft het competentiegerichte onderwijs een centrale plaats in de duale opleiding tot Physician Assistant (PA) waarbinnen de leerlijnen van het cur- riculum aansluiten bij het CanMEDS framework. ${ }^{3}$ Argumenten voor het inrichten van competentiegericht onderwijs zijn de maatschappelijke veranderingen, de wijzigingen van zorgvragen en de toename van complexiteit van zorg; al deze aspecten stellen nieuwe eisen aan medici en PA's. ${ }^{4}$ In aansluiting hierop worden eisen gesteld aan professionals wat betreft het vermogen zich blijvend te ontwikkelen. 
De kern van het competentiegerichte onderwijs is de integratie van de elementen kennis, vaardigheden en houding aan de hand van realistische beroepstaken. De praktijksituaties vormen de steigers voor het curriculum. ${ }^{5}$ Het competentiegericht opleiden kan de afstand tussen theorie en praktijk helpen verkleinen. Dit leerproces gaat uit van de specifieke werkzaamheden binnen het werkveld waardoor transparant wordt wat de werkgever concreet van de PA mag verwachten. De superviserende medicus leidt de PA in de praktijk op en beoordeelt of de competenties voldoende zijn getraind om gedelegeerde werkzaamheden uit te kunnen voeren. Van belang is dat de supervisor bekwaam is in het beslissen of de PA competent is en de verantwoordelijkheid kan dragen voor een uit te voeren professionele activiteit. 46

Deze toevertrouwde professionele activiteiten worden Entrustable Professional Activities (EPA's) genoemd. EPA's zijn kritische beroepsactiviteiten die samen het geheel vormen van elementen die een professie operationaliseren. ${ }^{6-7}$ De medicus kan een EPA toevertrouwen aan een PA op het moment dat hij/zij voldoende competenties heeft verworven om die activiteit zelfstandig uit te voeren. Vóór dat moment is er supervisie nodig, daarna niet meer. Supervisie is een leertraject onder leiding van een supervisor (docent/expert) waarin methodisch wordt ingegaan op de persoonlijke leervragen die iemand heeft ten aanzien van zijn werk. Dagelijks beslist de supervisor welke professionele activiteiten kunnen worden gedelegeerd aan de PA om met succes te worden uitgevoerd. De informatie op welke gronden deze beslissing wordt genomen door de supervisor is vaak impliciet. ${ }^{6}{ }^{8}$ In veel situaties moet de PA het vertrouwen van de supervisor winnen door in diens aanwezigheid te demonstreren hoe een EPA wordt uitgevoerd. De PA die competent is tot het uitvoeren van alle EPA's bezit het eindniveau van de opleiding. Maar dat betekent niet dat volledige expertise van routine is bereikt; de vaardigheid daarin groeit ook in de zelfstandige uitvoering.

Competentielevels kunnen worden ingepast: 1) novice, 2) advanced beginner, 3 ) competent, 4) proficient, 5) expert.9-10 $\mathrm{Bij}$ de beoordeling van EPA's kan gebruik worden gemaakt van Korte Praktijk Beoordelingen (KPB) en een portfolio. ${ }^{11}$

De EPA's hebben relaties met CanMEDS competentiegebieden en deze combinatie is als een matrix voor te stellen. Een EPA moet aan de volgende kenmerken voldoen:

- Het is een wezenlijk onderdeel van het werk in de lokale context.

- Het vereist een zekere mate van beroepsgerichte kennis, vaardigheid en/ of attitude.

- Het leidt tot een erkend en meetbaar werkresultaat.

- Het behoort tot het werk van de erkende beroepsbeoefenaar.

- Het is uitvoerbaar als afzonderlijke activiteit.

- Het is uitvoerbaar binnen een beperkt tijdsbestek.

- Het is observeerbaar en beoordeelbaar naar proces en product.

- Het weerspiegelt een of meer competenties uit het CanMEDS raamwerk.

Taakherschikking binnen het medisch domein is actueel en vraagt om onderzoek naar de effecten ervan op veiligheid, effectiviteit, toegankelijkheid en patiëntgerichtheid. ${ }^{12}$ Mede om deze reden is binnen Urologie gestart met een pilotonderzoek, gericht op het objectiveren van EPA's en bijbehorende competenties. Zowel urologen als PA's hebben tijdens de interviews informatie verstrekt over het delegeren van EPA's en het aanleren van de bijbehorende competenties. 
Voor de eenduidigheid, structuur en beoordeling van het leerproces is het belangrijk dat enerzijds de EPA's van de PA worden getraceerd en dat anderzijds kan worden vastgesteld of de tevoren geformuleerde algemene competenties zijn bereikt. De werkzaamheden die een PA kan verrichten binnen het medisch domein zijn divers: van differentiaal diagnose, anamnese, onderzoek tot behandeling en nazorg van de patiënt. Voorlichting en begeleiding van de patiënt behoort ook tot het takenpakket van de PA. Duidelijkheid en consensus over de taken die een PA kan uitvoeren binnen Urologie biedt naast continuïteit van zorg voor de patiënt ook ruimte aan de uroloog om zich te bekwamen in complexere zorg. De theorie van de EPA's en het framework van de CanMEDS dienen als kader voor de analyse en omschrijving van de taken en competenties van de PA binnen dit onderzoek. Het onderzoek had de volgende doelen:

- Het identificeren van de EPA's Urologie en het analyseren van de bijbehorende competenties van de PA.

- Het uitwerken van een tweedimensionale concept matrix van CanMEDS en EPA's Urologie.

- Het verhelderen van de aspecten supervisie en vertrouwen binnen de taakdelegatie van EPA's tussen uroloog en PA.

Deze doelstelling leidde tot de volgende vraagstelling:

- Welke EPA's en competenties uit het CanMEDS framework worden binnen het specialisme Urologie gedelegeerd van de uroloog naar de PA?

- Wat is de inhoud van de tweedimensionale conceptmatrix na toetsing door experts?

- Hoe wordt door urologen en PA's de aspecten supervisie en vertrouwen bij het delegeren van EPA's ingevuld?

\section{Methode}

De dataverzameling vond plaats tussen april en augustus 2007. Hiertoe werden urologen en PA's geïnterviewd aan de hand van semi-gestructureerde vragenlijsten. ${ }^{13}$ De tweedimensionale conceptmatrix is aan de hand van een literatuurreview en met behulp van de feedback tijdens interviews van PA's, urologen en opleidingsdeskundigen ontwikkeld. ${ }^{14-15}$

\section{Populatie}

Het onderzoek is uitgevoerd bij acht urologen en tien PA's Urologie. De genoemde professionals waren werkzaam binnen verschillende Universitaire Medische Centra en diverse andere ziekenhuizen. Van de tien PA's waren er tijdens het interview nog drie in opleiding. De geïncludeerde urologen hebben ervaring binnen het vakgebied Urologie en met het opleiden van medici (basisartsen, medisch specialisten en PA's). Vijf experts (twee PA's, één uroloog en twee opleiders PA) hebben de tweedimensionale matrix ingevuld en gecontroleerd.

\section{Instrument}

Vanuit de literatuurreview zijn vragenlijsten en een concept matrix ontwikkeld voor de urologen en PA's. ${ }^{13-15}$ De semi-gestructureerde vragenlijsten bestonden uit gesloten en open vragen en een concept matrix. Met behulp van de gesloten vragen is de patiëntpopulatie van de unit waar de PA werkzaam is in kaart gebracht. Door het stellen van de open vragen konden de aspecten supervisie en vertrouwen als onderdeel van het delegeren van EPA's van uroloog naar PA worden gedetermineerd. Met behulp van een tweedimensionale conceptmatrix zijn de EPA's Urologie en CanMEDS competenties tijdens ieder interview geïnventariseerd, gecontroleerd en aangevuld. Vervolgens is de conceptmatrix nader uitgewerkt en 
voorgelegd aan de vijf experts, met de vraag de matrix te controleren op volledigheid en van iedere EPA de kerncompetenties van het CanMEDS framework te analyseren.

\section{Dataverzameling en analyse}

Alle interviews zijn op een digitale recorder opgenomen, getranscribeerd, in werkbare scènes onderverdeeld, en met behulp van MAXQDA versie 2007 gecodeerd en geanalyseerd. ${ }^{16}$ MAXQDA is een softwarepakket dat administratieve ondersteuning biedt bij de analyse van kwalitatief onderzoek. Voor het analyseren van de data betreffende de aspecten supervisie en vertrouwen is gekozen voor de Grounded Theory benadering. ${ }^{17-18}$ Het verzamelen van zoveel mogelijk verschillende uitspraken over supervisie en vertrouwen leverde vanuit het perspectief van de urologen en PA's een gevarieerd beeld op. Het afnemen van interviews en het analyseren wisselden elkaar af in een iteratief proces. ${ }^{17}$ In ieder volgend interview zijn bestaande lacunes uitgediept om een duidelijk beeld te krijgen van de EPA's, de competenties en de delegatie van taken (met het accent op supervisie en vertrouwen). Na data-analyse van de interviews en verwerking in de tweedimensionale matrix is de matrix aan vijf experts voorgelegd. De experts hebben de EPA's gecontroleerd op volledigheid, waarna van iedere EPA de kerncompetenties van het CanMEDS framework zijn geanalyseerd.

\section{Resultaten}

Urologie is een specialisme dat zich bezighoudt met de problemen aan het urogenitale stelsel bij mannen, vrouwen en kinderen. De volgende pijlers kunnen worden onderscheiden:

- Functionele urologie

- Andrologische urologie

- Kinderurologie
- Minimale invasieve urologie

- Oncologische urologie

De werkzaamheden van de PA Urologie worden uitgevoerd binnen de polikliniek, de onderzoekkamers en de operatiekamers; twee PA's zijn ook werkzaam binnen de zogenaamde zaaldienst. Hiernaast worden consulten urologie uitgevoerd binnen andere afdelingen in het ziekenhuis. PA's zien patiënten met verschillende urologische afwijkingen, variërend van afvoerwegen van de nieren, urineblaas, plasbuis en prostaat, penis, testikel, bijbal en zaadleider. Naar gelang de afwijking die een patiënt heeft, is er samenwerking met kinderartsen, kinderchirurgen, neurologen, gynaecologen, seksuologen en fysiotherapeuten.

Dit pilotonderzoek heeft geleid tot het voor de PA determineren van 47 EPA's Urologie. Per EPA zijn de CanMEDS competenties van de PA geanalyseerd. Het accent van de competenties is divers en afhankelijk van de aard van de EPA. De tweedimensionale matrix objectiveert genoemde EPA's en competenties. Tabel 1 geeft voorbeelden van één generieke en één specifieke EPA met bijbehorende kerncompetenties van het CanMEDS framework. De 28 kerncompetenties zijn geformuleerd in lijn met het kaderbesluit van het Centraal College van Medische Specialismen, zoals verwoord in Bleker et al (2004). ${ }^{19}$ Dit is op vergelijkbare wijze voor alle 47 EPA's uitgewerkt.

De cijfers in de matrix geven per cel het aantal experts aan dat de kerncompetentie, passend bij de betreffende EPA, als vereist beschouwd. Hoe hoger het getal, hoe meer overeenstemming er bestaat tussen de experts. Bij vijf experts zou beargumenteerd kunnen worden dat relaties van drie of hoger staan voor een relevante koppeling. Het betreft hier echter een pilotstudie die nog bredere validering vergt. 


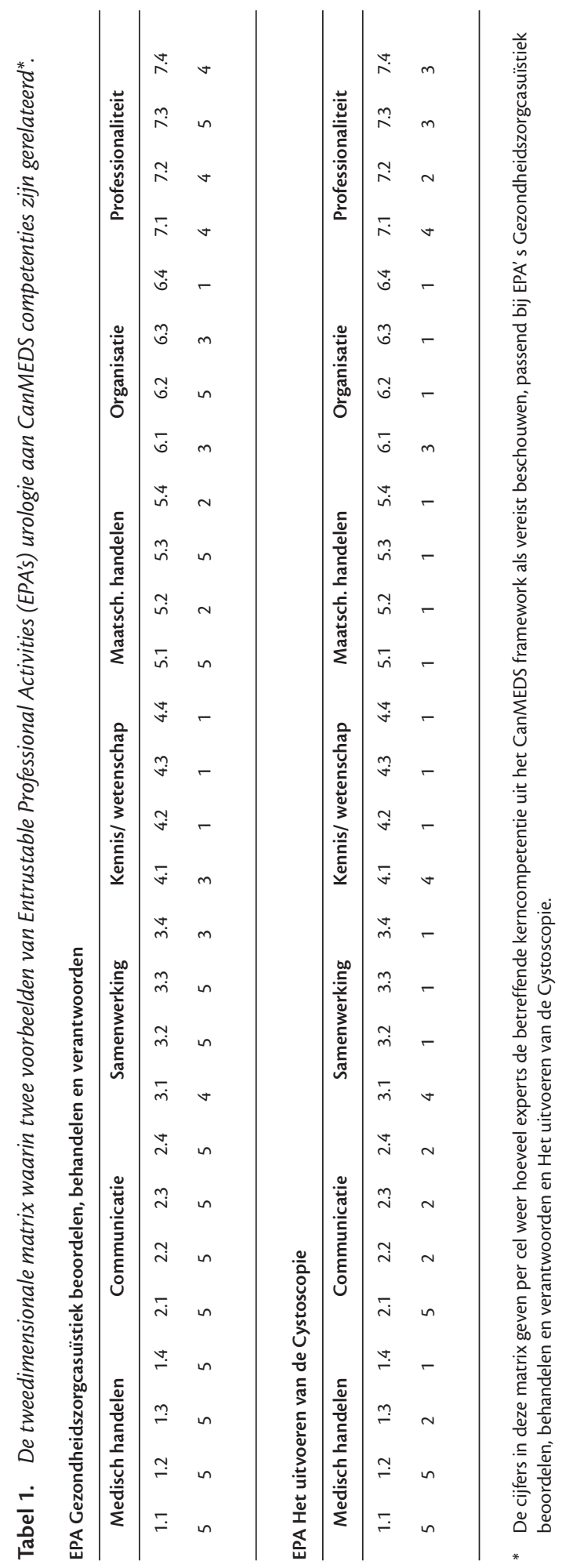




\section{Supervisie}

Supervisie is een leertraject onder leiding van een supervisor waarin methodisch wordt ingegaan op de persoonlijke leervragen die iemand heeft ten aanzien van zijn werk. Dagelijks beslist de supervisor welke EPA's kunnen worden gedelegeerd aan de PA om met redelijk succes te kunnen worden uitgevoerd. De informatie op welke gronden de supervisor deze beslissing neemt is vaak impliciet.Ter illustratie van dit proces volgen enkele citaten van urologen en PA's:

Uroloog '(...) ik test voorkennis, demonstreer, observeer de handeling en communiceer met patiënt en multidisciplinair, controleer en geeft steeds meer vrijheid. Iedere dag spreek en zie ik de PA, het vertrouwen groeit hierdoor.'

Uroloog '(...) in het begin is de supervisie strikt alles controleren of dit klopt en hierna steeds meer zelfstandigheid. Je let goed op of PA goed is in uitvragen van klachten en lichamelijk onderzoek. Gaandeweg kom je erachter of iemand goed is. Uit de vragen kun je veel afleiden.'

Uroloog '(...) in begin veel onderzoek samen doen en vragen wat voel je precies bij bv. rectaal toucher en dit vaak herhalen en samen doen en op gegeven moment snapt de PA wat je moet voelen. Op een gegeven moment zegt de PA ik voel iets bijzonders, dan weet je als uroloog er is iets aan de hand. Als de PA zegt het is goed dan vertrouw je dat als uroloog na genoemde procedure. Het is moeilijk aan te geven hoe superviseer je dat, kan ik geen duidelijk antwoord op geven.'

PA '(...) het eerste jaar was moeilijk, ik heb het tweede jaar een overstap gemaakt naar een andere supervisor een wat jongere uroloog. Deze uroloog is positief over taakher- schikking en de uitvoering van mijn werkzaamheden. Ik heb direct veel verantwoordelijkheden toebedeeld gekregen men wil eigenlijk direct een werknemer en niet veel aandacht besteden aan inwerkperiode PA.'

PA '(...) ben begonnen met observatie van verpleegkundige werkzaamheden b.v. Uro Dynamisch Onderzoek (UDO) en ben dit na inwerkperiode gaan uitvoeren. Inwerkperiode door supervisor, observatie, nabootsing, controle en bijsturing b.v. anamnese, consultvoering en onderzoeken UDO, cystoscopie, vena punctie, gynaecologisch onderzoek enz.'

\section{Vertrouwen}

Het toekennen van vertrouwen door de supervisor aan de PA is essentieel. Dagelijks beslist de supervisor welke professionele activiteiten kunnen worden gedelegeerd aan de PA om met redelijk succes te kunnen worden uitgevoerd. De informatie op welke gronden de supervisor deze beslissing neemt is vaak impliciet.

Uroloog '(...) Er moet een soort persoonlijke klik zijn met de PA. Ik lees de brieven van de PA en geef feedback en we houden een logboek bij. We checken ook of de leerdoelen worden gehaald. Je moet er wel energie insteken het kost in het begin energie, op het laatst verandert het niveau van insteken energie je krijgt er ook veel energie uit. Het eist toch wel veel contact.'

Uroloog '(...) Vertrouwen winnen is belangrijk. PA is aanwezig tijdens ingrepen bij arts assistent de kwaliteit van ingrepen is verhoogd. Bijvoorbeeld het uitvoeren van de Cystoscopie, dit proces verloopt nu echt volgens protocol omdat PA aanwezig is, uroloog heeft hiervoor geen tijd. Ook de $K K B$ beoordeling dit is zinvol, de PA kan dit net zo goed doen als Uroloog. Hierdoor is er veel minder wildgroei in behandelingen.' 
PA '(...) eerste jaar liep dit stroef de uroloog deed b.v. onderzoeken een keer voor en dan moest ik dit alleen kunnen. Dit heb ik geweigerd, voelde mij onzeker en de functie $P A$ wil ze goed neerzetten in dit ziekenhuis. Hierover moet je communiceren. De patiënten moeten vertrouwen hebben in PA.'

$P A$ '(...) Ja, dat gevoel van vertrouwen had $i k$ met mijn opleider. Ik kan goed mijn grenzen aangeven dit is aller belangrijkst, je moet heel goed kunnen communiceren en ventileren. Door je gedachtegang bekend te maken moet ook inzichtelijk worden wat je niet ziet. De klinische blik kunnen verwoorden, de red flags kunnen zien.'

\section{Conclusie en beschouwing}

Dit pilotonderzoek heeft niet alleen geleid tot het determineren van 47 EPA's Urologie maar heeft bovendien een empirisch gefundeerde matrix opgeleverd voor de samenhang tussen EPA's en CanMEDS competenties. Deze matrix is bruikbaar bij het opleiden van PA's, zowel wat betreft de theorie als de praktijk. Het verleent de uroloog en de PA handvatten om de werkzaamheden meer te structureren en de opleiding zoveel mogelijk te laten aansluiten bij de activiteiten op de werkvloer. Gerichte bijstelling van het curriculum van de masteropleiding PA is mogelijk naast het aanpassen van het onderwijs. Bij iedere EPA Urologie wordt aangegeven waar het accent dient te liggen bij het aanleren van de passende competenties. Leren uitvoeren van EPA's door de PA vereist supervisie en vertrouwen van de uroloog. De interviews hebben de basis gelegd voor het kunnen objectiveren van beide begrippen.

Supervisie: Dit is een leertraject onder leiding van een supervisor waarin methodisch wordt ingegaan op de persoonlijke leervragen die iemand heeft ten aanzien van zijn werk. Bij het aanleren van een
EPA dient de uroloog aanwezig te zijn voor observatie en beoordeling van de competentie. EPA's aanleren gaat volgens de opeenvolgende stappen: kennis uitvragen, demonstreren en uitvoeren onder begeleiding tot uiteindelijk het zelfstandig uitvoeren. Uit de door de PA gestelde vragen kan de supervisor afleiden of de competenties kennis, analyse en synthese voldoende aanwezig zijn.

Vertrouwen: Het opbouwen van wederzijds vertrouwen tussen uroloog en PA heeft tijd nodig en blijft een subjectief gevoel. De uroloog volgt de PA en geeft telkens meer vrijheid. Het aangeven van grenzen is belangrijk naast het optimaal communiceren en ventileren. De PA dient de klinische blik en 'red flags' te verwoorden; dit geeft wederzijds vertrouwen.

\section{Aanbevelingen}

In dit pilotonderzoek zijn de EPA's en kerncompetenties van het CanMEDS framework in het opleidingstraject van de PA Urologie verkend in een kleine groep. Vergroting van de onderzoeksgroep is noodzakelijk om consensus over de inhoud van de tweedimensionale matrix binnen de doelgroep urologen en PA's te bereiken. Dit is mogelijk door de matrix die is ontstaan te valideren via een grote steekproef onder urologen en PA's. Taakherschikking in de gezondheidszorg is actueel en krijgt invulling door EPA's te delegeren naar PA's of artsen in opleiding. Supervisie en vertrouwen is hierbij belangrijk en vraagt om nadere objectivering. Dit onderzoek kan worden uitgebreid naar andere specialismen waar PA's worden opgeleid zodat de validiteit en betrouwbaarheid kan worden vergroot.

\section{Dankwoord}

Zonder hulp van de urologen en Physician Assistants zou dit onderzoek niet plaats hebben kunnen vinden. Daarnaast zijn de 
auteurs dank verschuldigd aan mw. drs. M. Sinoo voor haar hulp bij het coderen van de interviews en suggesties bij de opzet, uitvoering en omschrijving van het onderzoek.

\section{Literatuur}

1. Rademakers JJDJM, De Rooy N, Ten Cate ThJ. Senior medical students' appraisal of CanMEDS competenties. Med Educ 2007;41(10):990-94.

2. CanMeds 2005. Skills for the new Millennium: report of the societal needs working group. Available at: http://www.healthcare.ubc.ca/residency/ CanMEDS_2005_Framework.pdf. The royal college of Physicians and Surgeons of Ottawa Canada; 2005.

3. Spenkelink-Schut G, Koch RPP, Kort HSM. De Physician Assistant "Een nieuwe masteropleiding binnen het medisch domein van de gezondheidszorg in Nederland". Onderwijs en Gezondheidszorg 2006;5:18-22. [The Physician assistant: A new master's course in health care education in the Netherlands. Education and Health Care 2006;5:18-22].

4. Studiegids Master Opleiding Physician Assistant Hogeschool Utrecht 2007/2008. [Syllabus of the Physician Assistant Master's Course. Hogeschool Utrecht University for Applied Sciences 2007/ 2008].

5. Schlusmans K, Slotman R Nagtegaal C, Kinkhorst G. Competentiegerichte leeromgevingen. Utrecht: Lemma; 1999. [Competence-based Learning Environments. Utrecht: Lemma; 1999].

6. Ten Cate ThJ. Entrustable professional activities in competency-based training. Med Educ 2005;39(10):1176-77.

7 Ten Cate ThJ. Trust, competence, and the supervisor's role in postgraduate training. BMJ 2007; 333:748-751.

8. Ten Cate THJ, Scheele F. Competency-Based Postgraduate Training: Can we Bridge the Gap between Theory and clinical Practice. Academic Medicine 2007;82(6):542-47.

9. Dreyfus HL,Dreyfus SE. Mind over machine: the power of human intuition and expertise in the area of the computer. Oxford: Basil Blackwel; 1986.

10. Benner P. From novice to expert. Excellence and power in clinical nursing practice. Menlo Park: Addison-Wesley; 1984.

11. Schuwirth LWT, Vleuten CPM van der. Competentiegerichte toetsing in het klinisch onderwijs. Ned Tijdschr Geneeskd 2005;149(9):2752-55. [Competence-based assessment in clinical education. Dutch Journal of Medicine 2005;149(9) 2752-55].

12. Inspectierapport Staat van de Gezondheidszorg; Taakherschikking blijkt positief voor de kwaliteit van zorg. Den Haag: Inspectie voor de gezondheidszorg; 2007. [Inspection Report on the State of Health Care; Task redistribution appears to have a positive impact on the quality of care. The Hague: The Netherlands Health Care Inspectorate; 2007].

13. Baarda DB, Goede MPM de, Teunissen J. Basisboek kwalitatief onderzoek: praktische handleiding voor het opzetten en uitvoeren van kwalitatief onderzoek, $2 \mathrm{dr}$. Groningen: Stenford Kroese; 2005. [Basic Book on Qualitative Research: a Practical Guide for Designing and Conducting Qualitative Research, 2 ed. Groningen: Stenford Kroese;2005].

14. Bangma CH. Urologie. Bohn Stafleu Van Loghum: Houten/Mechelen; 2002. [Urology. Bohn Stafleu Van Loghum: Houten/Mechelen;2002].

15. Kumar P, Clark M. Clinical Medicine: Edinburgh: Saunders WB; 2002.

16. MAXQDA site; http://www.maxqda.com/ [visited 8-8-08]

17. Polit DF, Hungler BP. Nursing Research Principles and Methods: Lippingcott Compeny; Philadelphia: 1999.

18. Morse JM, Field PA. Nursing Research. The application of qualitative approaches: Stanley Thornes (Publishers) Ltd; Cheltenham United Kingdom: 1998.

19. Bleker OP, Cate ThJ ten, Holdrinet RSG. De algemene competenties van de medisch specialist in de toekomst. Tijdschrift voor Medisch Onderwijs 2004;23(1):4-14. [General competencies of the future medical specialist. Dutch Journal of Medical Education 2004;23(1)4-14].

De auteurs:

Mw. G. Spenkelink-Schut is MSc Senior Opleider Adviseur/Onderzoeker Kenniscentrum Innovatie van Zorgverlening: Lectoraat Vraaggestuurde Zorg Hogeschool Utrecht.

Prof. dr. Th.J. ten Cate is hoogleraar medische onderwijskunde en directeur van het Expertisecentrum voor Onderwijs en Opleiding van het Universitair Medisch Centrum Utrecht.

Mw. dr. H.S.M. Kort is lector Vraaggestuurde Zorg; Kenniscentrum Innovatie van Zorgverlening, Hogeschool Utrecht.

Correspondentieadres:

Mw. G.Spenkelink-Schut, Kenniscentrum Innovatie van Zorgverlening, Hogeschool Utrecht, Bolognalaan 101, 3584 CJ, Postbus 85182 AD Utrecht.Tel: 0302585278;e-mail: geesje.spenkelink-schut@hu.nl

Belangenconflict: geen gemeld

Financiële ondersteuning: geen gemeld 


\section{Summary}

Introduction: The aim of this study was to identify Entrustable Professional Activities (EPAs) for Physician Assistants (PAs) in urology and to determine core competencies for urology PAs based on the CanMEDS (Canadian Medical Education Directions for Specialists) framework.

Methods: In a pilot study, PAs and urologists participated in interviews in which a semi-structured questionnaire was administered. Based on the data from the interviews, a two-dimensional matrix was constructed combining EPAs and CanMEDS competencies. Five experts examined the matrix to determine whether all EPAs were included and whether the CanMEDS framework had been used appropriately. The responses to the open-ended questions about supervision and trust in relation to delegating EPAs were analysed using a grounded theory approach

Results: Forty-seven EPAs for urology PAs were included in a two-dimensional matrix to objectify the EPAs and the CanMEDS competencies. PAs need supervision and trust from urologists in learning how to perform the EPAs. The steps of the learning process comprise: assessing knowledge, demonstrating, supervised performance, independent performance. During the learning process the urologist should observe, guide and assess the PA's performance. Building mutual trust between the urologist and the PA takes time and will remain a subjective aspect of the learning process, in which excellent communication as well as setting boundaries are key factors.

Conclusions: The pilot study yielded an empirically based model representing the interrelationships of EPAs and CanMEDS competencies. The preliminary results from this pilot study can be used in training urology PAs, but further studies are recommended. (Spenkelink-Schut G, Cate Th.J. ten, Kort HSM. Applying the concept of Entrustable Professional Activities to link CanMEDS competencies with the workplace: a pilot study of the physician assistant workforce in urology. Dutch Journal of Medical Education 2008;27(5):230-238.) 